\title{
Nonmotor Symptoms of Parkinson's Disease as Predictors of Dementia
}

\author{
Mohammed Wasif Hussain, Richard Camicioli
}

\begin{abstract}
Some nonmotor symptoms (NMS) of Parkinson's disease (PD) have been shown to increase the risk of developing dementia. A total of 52 PD patients without dementia at baseline were examined for NMS over 36 months. Mini-Mental State Examination, Dementia Rating Scale-2, and caregiver-derived (Clinical Dementia Rating) scores were employed to rate patients as having either clear progression or not. Some 20 of 48 participants $(41.7 \%)$ had clear cognitive decline. Univariate binary regression analysis was statistically significant for age (odds ratio $\left.[O R]\left(C I_{95 \%}\right)=1.24,1.07-1.45, p=0.006\right)$ and orthostatic hypotension $(\mathrm{OH})\left(O R\left(C I_{95 \%}\right)=4.91,1.24-19.5\right.$, $p=0.024)$. Multivariate analysis showed that only age $\left(O R\left(C I_{95 \%}\right)=1.19,1.0-1.41, p=0.05\right)$ and $\mathrm{OH}\left(O R\left(C I_{95 \%}\right)=5.57,1.0-30.97\right.$, $p=0.05)$ were correlated with an increased risk of cognitive decline. The presence of $\mathrm{OH}$ at baseline may be a significant predictor of progression to dementia in PD.

RÉSUMÉ: Les symptômes non moteurs associés à la maladie de Parkinson peuvent être des prédicteurs de la démence. Il a été prouvé que certains symptômes non moteurs associés à la maladie de Parkinson peuvent augmenter le risque de souffrir de démence. Un total de 52 patients parkinsoniens ne souffrant d'aucune démence au moment d'amorcer cette étude ont été suivis pendant 36 mois afin d'établir ou non la présence de ces symptômes non moteurs. Les score obtenus à l'aide de divers outils (le test de Folstein ou Mini-Mental State Examination; l'échelle de démence de Mattis ou Dementia Rating Scale-2 ; basée sur les observations du personnel soignant, l'évaluation clinique de la démence ou Clinical Dementia Rating) ont été utilisés afin d'évaluer les patients et de déceler une possible progression de ces symptômes non moteurs. Sur 48 patients, 20 (41,7\%) ont manifesté un déclin cognitif patent. Une analyse de régression binaire à une variable s'est révélée statistiquement significative en ce qui regarde l'âge (rapport de cotes $\left.[R C]\left(I C_{95 \%}\right)=1,24 ; 1,07-1,45 ; p=0,006\right)$ et l'hypotension orthostatique (rapport de cotes $\left.[R C]\left(I C_{95}\right)=4,91 ; 1,24-19,5, p=0,024\right)$. Une analyse multi-variée de données a par ailleurs montré que seuls l'âge (rapport de cotes $\left.[R C]\left(I C_{95 \%}\right)=1,19 ; 1,0-1,41 ; p=0,05\right)$ et l'hypotension orthostatique (rapport de cotes $[R C]\left(I C_{95 \%}\right)=5,57 ; 1,0-30,97$, $p=0,05$ ) étaient liés à une augmentation du risque d'être atteint de déclin cognitif. Il se pourrait donc que la présence, chez des patients parkinsoniens, de l'hypotension orthostatique soit un prédicteur notable de la progression vers la démence.
\end{abstract}

Keywords: Parkinson's disease, Nonmotor symptoms, Dementia, Cognitive decline, Prospective, Orthostatic hypotension

doi:10.1017/cjn.2017.239

Can J Neurol Sci. 2018; 45: 97-99

Parkinson's disease (PD) is diagnosed clinically by its classic triad of rest tremor, rigidity, and bradykinesia. These motor symptoms are the hallmark of the disease, but recent studies have highlighted the less-understood nonmotor symptoms (NMS) that may in part be related to pathology outside of the substantia nigra. ${ }^{1}$ These symptoms include smell disturbance, sleep disturbance (including rapid eye movement [REM] sleep behavior disorder), autonomic dysfunction, apathy, mood changes, and cognitive impairment. They may predate motor symptoms and are related to quality of life. ${ }^{1}$ Recent studies have shown that patients with specific NMS appear to have an increased likelihood of having or developing others. Baba et al. ${ }^{2}$ showed that over a 3 -year period 10 of $24(42 \%)$ PD patients with significant loss of smell developed dementia while none of the $20(0 \%)$ PD controls without significant smell disturbance did. Similarly, Dujardin et al. ${ }^{3}$ studied PD patients with and without apathy and over an 18-month period found development of dementia in $8 / 20(40 \%)$ and $1 / 20(5 \%)$, respectively. A more recent paper by Anang et al. ${ }^{4}$ showed an increased risk of dementia with the baseline presence of REM sleep behavior disorder (RBD), orthostatic hypotension $(\mathrm{OH})$, color discrimination, and gait disorder. This was further validated using two additional prospective cohorts suggesting age, sex, RBD, $\mathrm{OH}$, and mild cognitive impairment as being significantly associated with dementia. ${ }^{5}$ A recent review paper ${ }^{6}$ concluded that there appears to be a link between $\mathrm{OH}$ and cognitive impairment in PD, but it is unclear if this link is associative or causative. These studies suggest that PD patients who present with NMS without cognitive issues have an added risk of developing dementia over time. We aimed to further understand the connection between various NMS and the development of cognitive impairment in our population. We hypothesized that the presence of NMS - especially autonomic, olfactory, and neuropsychiatric features-at presentation would predict the progression of cognitive impairment.

Ethics approval was obtained by the university's human research ethics board from the biomedical department, and informed consent was obtained prior to enrollment into the study for all participants. We enrolled a total of 52 patients as part of a longitudinal study. This patient population is as described by

From the Department of Medicine, Division of Neurology, University of Alberta, Edmonton, Alberta, Canada (MWH); the Division of Neurology, University of Alberta, Edmonton, Alberta, Canada (RC).

Received December 7, 2016. Final Revisions Submitted June 27, 2017. Date of ACCEPTANCE June 30, 2017.

Correspondence to: Mohammed Wasif Hussain, Department of Medicine, Division of Neurology, University of Alberta, 8440-112 Street, Edmonton, Alberta, Canada, T6G 2B7. Email: mhussain@ualberta.ca. 
Camicioli et al. ${ }^{7}$ Patients had a clinical diagnosis of PD without significant cognitive impairment that interfered with function at baseline and were followed over a 36-month period. As previously described, ${ }^{7}$ we conducted a standardized neurological exam as well as assessments for NMS at baseline, 18 months, and 36 months. For the purpose of our study, the NMS screen included: psychiatric (mood and other behavioral changes) using the Neuropsychiatric Inventory for depression (NPI-Depression) (www.npitest.net) and for apathy (NPI-Apathy); olfactory function via the Brief Smell Identification Test (BSIT) and patient report of smell loss; sleep disturbances via the Mayo Fluctuation Scale, ${ }^{8}$ NPI-Sleep, and the modified Epworth Sleepiness Scale; ${ }^{9}$ and dysautonomia via an examination of orthostatic vitals in the lying, sitting, and standing positions. Orthostatic hypotension $(\mathrm{OH})$ was defined as a drop of at least $20 \mathrm{mmHg}$ of systolic pressure or $10 \mathrm{mmHg}$ of diastolic pressure from lying to sitting or standing position or sitting to standing position if a patient was unable to tolerate lying flat. One patient was considered as having $\mathrm{OH}$ due to having borderline orthostatic hypotension (systolic drop of $16 \mathrm{mmHg}$ ) from lying to sitting, but felt so symptomatic that he was unable to attempt a standing position. The study neurologist and research assistant completed separate patient and caregiver interviews as well as patient assessments.

Our dependent variable was cognitive decline, and, as in our previous study, cognitive decline was assessed using a combination of the Mini-Mental Status Examination (MMSE), the Frontal Assessment Battery (FAB), the Dementia Rating Scale (DRS), and caregiver-derived (CDR) scores. ${ }^{7}$ Patients were assigned binary results as either having or not having clear cognitive decline based on the above scores and the clinical impression of the research neurologist (taking into account all information, including patient assessment, cognitive scores, and caregiver report based on a semistructured interview).

Over the course of our study, four patients were not included in the final analysis: two were excluded due to death and two were dropouts.

First, univariate analyses for each NMS as well as age, education, sex, and duration of Parkinson's disease were performed (Table 2). Next, we performed a multivariate binary regression analysis for each NMS that had at least a significance of $p<0.1$ on univariate analysis as well as all demographic features (adjusting for age, sex, education, and PD duration). A separate analysis was also conducted for levodopa equivalent dose, ${ }^{9}$ but given the confounding with duration of $\mathrm{PD}$, it was excluded from the final analysis. A $p$ value of 0.05 was considered statistically significant in this exploratory study.

We studied 48 patients with a mean age of 71.5 and median PD duration of 8.9 years (Table 1). The average MMSE was 28.1 at baseline and decreased to 26.5 at 36 months; the baseline FAB score was 14.5 , which decreased to 13.7 at 36 months. Over the course of our study, 20 of 48 (41.7\%) patients were deemed to have significant cognitive decline (Table 2). In patients with cognitive decline, the average MMSE score was 27.1 at baseline and 24.0 at 36 months; baseline FAB was 13.7, which decreased to 11 at 36 months. Some 13 of $48(27 \%)$ patients were found to have $\mathrm{OH}$ at baseline, with a mean drop in systolic blood pressure of $30.9 \mathrm{mmHg}$ and in diastolic blood pressure of $16 \mathrm{mmHg}$. A total of 11 of these $13(84.6 \%)$ went on to have clear cognitive decline, whereas 9 of 35 (26\%) patients without baseline $\mathrm{OH}$ had cognitive decline. Some 11 of 20 (55\%) patients with cognitive decline had $\mathrm{OH}$ at baseline. Of the 9 patients with cognitive decline without baseline orthostatic hypotension, the

\section{Table 1: Testing results at 0 and 36 months}

\begin{tabular}{|c|c|c|}
\hline Measures & $\begin{array}{c}\text { Mean }(S D) \text { at } 0 \text { months, } \\
n(\%)\end{array}$ & $\begin{array}{c}\text { Mean }(S D) \text { at } 36 \text { months, } \\
n(\%)\end{array}$ \\
\hline \multicolumn{3}{|l|}{ Sex } \\
\hline Male & $27(56.3)$ & - \\
\hline Female & $21(43.7)$ & - \\
\hline Age & $71.5(4.8)$ & - \\
\hline Education & $14.1(3.0)$ & - \\
\hline PD duration & $8.9(4.5)$ & - \\
\hline Levodopa equivalence & $632.6(349)$ & $700.1(437)$ \\
\hline UPDRS III & $16.6(8.1)$ & 20.7 (11) \\
\hline UPDRS total & $26.6(12.9)$ & $33.0(17.4)$ \\
\hline MMSE & $28.1(1.7)$ & $26.5(3.5)$ \\
\hline FAB & $14.5(2.2)$ & $13.7(3.3)$ \\
\hline Dementia progression & - & $20(41.7)$ \\
\hline Smell score & $6.7(2.9)$ & - \\
\hline$\overline{\text { NPI }}$ & $5.2(7.6)$ & - \\
\hline Sleep (NPI) & $1.5(2.8)$ & - \\
\hline Sleep (Epworth) & $7.2(4.1)$ & - \\
\hline Sleep (Mayo fluctuation) & $0.6(0.8)$ & - \\
\hline Apathy (NPI) & $0.7(2.4)$ & - \\
\hline Orthostatic hypotension & $13(27 \%)$ & - \\
\hline
\end{tabular}

$\mathrm{FAB}=$ Frontal Assessment Battery; MMSE $=$ Mini-Mental State Examination; NPI = Neuropsychiatric Inventory; $\mathrm{PD}=$ Parkinson's disease;

UPDRS = Unified Parkinson's Disease Rating Scale

mean drop in systolic blood pressure was 0.22 , and there was a mean increase of 3.3 in diastolic blood pressure.

In the univariate binary regression analysis with cognitive decline versus no progression as our dependent variable, statistically significant results were found for age $\left(O R\left(C I_{95 \%}\right)=1.24\right.$, $1.07-1.45, p=0.006)$ and $\mathrm{OH}\left(\mathrm{OR}\left(C I_{95 \%}\right)=4.91,1.24-19.5\right.$, $p=0.024)$. Among the NMS, only $\mathrm{OH}$ and BSIT smell score $(p=0.075)$ had $p$ values below 0.1 , and thus NPI-Sleep score, Epworth Scale score, Mayo Fluctuation Scale score, and NPIDepression and NPI-Apathy scores (all $p>0.1$ ) were excluded from the multivariate analysis (Table 2).

A binary multivariate logistic regression analysis was performed to predict cognitive decline versus no cognitive decline based on the independent variables of $\mathrm{OH}$ and BSIT smell scores that were adjusted for age, sex, education, and PD duration. A significant regression equation was found $(p=0.007$, with a Cox and Snell $R^{2}$ and Nagelkerke $R^{2}=0.309$ and 0.416 , respectively). Compared to the no cognitive decline group, the cognitive decline group was more likely to have baseline $\mathrm{OH}\left(\mathrm{OR}\left(C_{95 \%}\right)=5.57\right.$, $1.0-30.97, p=0.05)$. There was no association with smell scores $\left(O R\left(C I_{95 \%}\right)=0.81,0.61-1.07, p=0.142\right)$.

In this prospective cohort study, we found that, of the variables selected, other than age, the presence of orthostatic hypotension was the only independent predictor of cognitive change.

This result adds further evidence to the recent literature that showed a link between orthostatic hypotension and cognitive decline. ${ }^{10}$ Like the study by Anang et al., ${ }^{4}$ we also did not find neuropsychiatric features or hyposmia to be predictors of dementia. 
Table 2: Binary univariate and multivariate analysis with cognitive decline as the dependent variable

\begin{tabular}{|c|c|c|c|c|c|c|}
\hline Variable & $\begin{array}{c}\text { Univariate } O R \\
\left(C I_{95 \%}\right)\end{array}$ & Univariate ( $p$ value) & $B$ & $S E$ & $\begin{array}{c}\text { Multivariate } O R \\
\left(C I_{95 \%}\right)\end{array}$ & Multivariate ( $p$ value) \\
\hline Age & $1.24(1.07-1.45)$ & $0.006^{*}$ & 1.71 & 0.09 & $1.19(1.0-1.41)$ & $0.05^{*}$ \\
\hline Sex & $1.09(0.34-3.47)$ & 0.883 & 0.35 & 0.83 & $1.42(0.28-7.22)$ & 0.673 \\
\hline Education & $0.85(0.68-1.07)$ & 0.158 & -0.03 & 0.14 & $0.97(0.74-1.27)$ & 0.806 \\
\hline PD duration & $1.11(0.97-1.27)$ & 0.127 & 0.09 & 0.09 & $1.09(0.91-1.31)$ & 0.352 \\
\hline $\mathrm{OH}$ & $4.91(1.24-19.5)$ & $0.024 *$ & 1.72 & 0.88 & $5.57(1.0-30.97)$ & $0.05^{*}$ \\
\hline Smell & $0.82(0.66-1.02)$ & 0.075 & -0.21 & 0.14 & $0.81(0.61-1.07)$ & 0.142 \\
\hline NPI-Sleep & $0.79(0.60-1.05)$ & 0.106 & - & - & - & - \\
\hline Epworth Sleep Scale & $1.00(0.86-1.17)$ & 0.99 & - & - & - & - \\
\hline Mayo Fluctuation Scale & $1.54(0.76-3.13)$ & 0.227 & - & - & - & - \\
\hline NPI-Depression & $1.04(0.77-1.39)$ & 0.81 & - & - & - & - \\
\hline NPI-Apathy & $1.24(0.87-1.78)$ & 0.233 & - & - & - & - \\
\hline
\end{tabular}

* = statistically significant; NPI = Neuropsychiatric Inventory; OH = orthostatic hypotension; PD = Parkinson's disease.

Unlike their study, however, we did not find sleep disturbancesusing the modified Epworth Sleepiness Scale, the NPI-Sleep item, and the Mayo Fluctuation Scale-to be significant predictors of cognitive decline. This may be related to the lack of a specified diagnosis of REM sleep behavior disorder in our study. These results are not in keeping with such other studies as Baba et al., ${ }^{2}$ which appeared to show a link between anosmia and cognitive decline.

Our results support the suggestion that $\alpha$-synuclein pathology in autonomic centers may precede spread to cortical areas involved in memory and higher cognitive function within a 36-month period. ${ }^{6,10}$ It remains possible that dysautonomia as measured by orthostatic change might contribute to cognitive decline. Other areas associated with NMS, such as smell and neuropsychiatric features, may still be related, but we were not able to ascertain this within the limited timespan of our study.

The limitations of our study include its short time frame, considering the facts that PD is a chronic neurodegenerative condition, that the presence of pathology is known to occur much earlier in some areas than others, and that changes may progress over time. Dopaminergic medications used might confound our findings, but our analysis, adjusting for duration of disease, was analogous to that of Anang et al. ${ }^{5}$ Our study is also limited by its relatively small sample size, which may not provide high enough power to identify some risks that have a weaker association. In addition, our study did not include more direct measures of REM sleep behavior disorder and color discrimination to confirm the findings of recently published data. Nevertheless, our study was prospective, with standardized measures of specific nonmotor symptoms and signs as well as detailed assessment of cognitive decline.

Our study provides further evidence that the presence of orthostatic hypotension is a significant predictor of progression to dementia in PD.

\section{Disclosures}

Richard Camicioli reports grants from the Canadian Institutes of Health Research during the conduct of the study; grants from the NIH, grants from the Alzheimer's Society, and grants from the University Hospital Foundation outside the submitted work. Mohammed Wasif Hussain has nothing to disclose.

\section{Statement of Authorship}

Dr. Richard Camicioli was the investigator who organized and executed the research project. He examined all patients and collected all the data presented. He also reviewed and critiqued the final manuscript. Dr. Mohammed Wasif Hussain conceived the idea for the study with Dr. Camicioli, reviewed the data presented, created the research question, and conducted the statistical analysis, as well as writing the first draft of the final paper.

\section{REFERENCES}

1. Chaudhuri KR, Healy DG, Schapira AH. Non-motor symptoms of Parkinson's disease: diagnosis and management. Lancet Neurol. 2006;5(3):235-45.

2. Baba T, Kikuchi A, Hirayama $K$, et al. Severe olfactory dysfunction is a prodromal symptom of dementia associated with Parkinson's disease: a 3-year longitudinal study. Brain. 2012; 135(1):161-9.

3. Dujardin K, Sockeel P, Delliaux M, Destee A, Defebvre L. Apathy may herald cognitive decline and dementia in Parkinson's disease. Mov Disord. 2009;24(16):2391-7.

4. Anang JB, Gagnon JF, Bertrand JA, et al. Predictors of dementia in Parkinson disease: a prospective cohort study. Neurology. 2014;83(14):1253-60.

5. Anang JB, Nomura T, Romenets SR, Nakashima K, Gagnon JF, Postuma RB. Dementia predictors in Parkinson disease: a validation study. J Parkinsons Dis. 2017;7(1):159-62.

6. McDonald C, Newton JL, Burn DJ. Orthostatic hypotension and cognitive impairment in Parkinson's disease: causation or association? Mov Disord. 2016;31(7):937-46.

7. Camicioli R, Sabino J, Gee M, et al. Ventricular dilatation and brain atrophy in patients with Parkinson's disease with incipient dementia. Mov Disord. 2011;26(8):1443-50.

8. Ferman TJ, Smith GE, Boeve BF, et al. DLB fluctuations: specific features that reliably differentiate DLB from AD and normal aging. Neurology. 2004;62(2):181-7.

9. Hobson DE, Lang AE, Martin W, Razmy A, Rivest J, Fleming J. Excessive daytime sleepiness and sudden-onset sleep in Parkinson disease: a survey by the Canadian Movement Disorders Group. JAMA. 2002;287(4):455-63.

10. Udow SJ, Robertson AD, MacIntosh BJ, et al. "Under pressure": is there a link between orthostatic hypotension and cognitive impairment in $\alpha$-synucleinopathies? J Neurol Neurosurg Psychiatry. 2016;87(12):1311-21. 